\title{
Más allá de un simple registro: reflexiones sobre la gestión estratégica de la propiedad intelectual en las empresas
}

\author{
Gustavo M. Rodríguez García y Maritza Agüero Miñano
}

La importancia de la propiedad intelectual es, hoy más que nunca, indiscutible. Sin embargo, la visión que muchas empresas suelen tener de la propiedad intelectual es considerablemente estrecha, porque pierden de vista que la propiedad intelectual nos presenta opciones que trascienden la mera acumulación de activos para su empleo tradicional y su defensa ocasional. En efecto, convencionalmente, se suele creer que la propiedad intelectual opera como una espada y un escudo. Una espada, porque permite atacar a los competidores al oponérseles los derechos de exclusiva obtenidos; un escudo, para cubrirse de las acciones que la competencia podría pretender. Aunque es válido pensar en estos términos, se trata, como ya dijimos, de una visión estrecha de la propiedad intelectual.

De manera más general, el sistema legal debe implementar estrategias para revelar información a los individuos sobre la vasta gama de alternativas disponibles, en el marco de una política pública de promoción de las innovaciones. La innovación no solo beneficia al titular de la propiedad intelectual, también genera beneficios en la sociedad en su conjunto, aunque no haya pagado directamente por tales beneficios (externalidades positivas). De manera sencilla, siguiendo a Greenhalgh y Rogers (2010), podemos definir la innovación como la aplicación de nuevas ideas a productos, procesos $u$ otros aspectos de las actividades 
de una empresa, y que generan un incremento del "valor", definido este como la sumatoria del "valor agregado" para la empresa y el "valor agregado" para los consumidores y otras empresas.

Cuando nos referimos a una innovación de producto, aludimos a la introducción de productos nuevos o de productos ya existentes pero con cambios sustantivos. Cuando nos referimos, en cambio, a una innovación de proceso, se trata de la implementación de una nueva forma de hacer o proporcionar productos o servicios. No necesariamente estamos ante innovaciones independientes, sino que suele ocurrir que la introducción de un nuevo proceso permite la generación de nuevos productos.

Asimismo, las innovaciones pueden ser incrementales (cuando un producto o proceso ya existe en el mercado y se le realiza una variación y/o adaptación para que realice una función diferente, o cuando resulta diferente en el marco de un determinado entorno o sector preexistente) o radicales o disruptivas. Estas últimas son aquellas que implican la aparición de nuevos productos, servicios o procesos que originariamente han sido complejos, costosos, y a los que solo pueden tener acceso un grupo de personas. A través de las innovaciones disruptivas, los productos, servicios o procesos son transformados para ser más accesibles y llegar a un mayor número de personas, lo cual hace que las innovaciones iniciales sucumban frente a las que irrumpen en el mercado ${ }^{1}$, como fue en su momento el caso de los ordenadores personales, que desplazaron a las computadoras creadas a inicios de la década de los años ochenta, o como en el caso de la penicilina, que inicialmente se desarrollaba con la grasa del cerdo y originaba enfermedades por la transmisión de virus de dicho animal al cuerpo humano, lo cual quedó

1 El profesor Clayton Christensen fue el creador de dicho término al explicar cómo las empresas que en sus inicios cuentan con menores márgenes brutos, pequeños mercados de destino y simples productos y servicios, pueden no parecer tan atractivas cuando son comparadas con las empresas dominantes del mercado. En tal sentido, es debido a dichas condiciones (niveles más bajos del mercado, ofrecen menores márgenes brutos, son poco atractivas para otras empresas) que tales empresas se mueven hacia arriba, creando un espacio en la parte inferior del mercado de los nuevos competidores para emerger y sobresalir del estadio preexistente, para llegar a disrumpir, dominar un determinado mercado y desplazar a las empresas dominantes en el mismo, hasta, incluso, hacerlas desaparecer. Fuente: http://www.claytonchristensen.com/key-concepts/ 
superado por su desarrollo a través de bacterias, que es lo que actualmente se utiliza.

El sistema de propiedad intelectual no es la única vía para fomentar las innovaciones, pero es ciertamente una de las más empleadas y útiles. La idea general es que si los derechos de propiedad intelectual (DPI) se encuentran adecuadamente definidos y son susceptibles de protección legal efectiva, y además existe la posibilidad de celebrar acuerdos privados en torno a esa propiedad intelectual, el mercado podría encaminarse hacia un nivel adecuado de innovación.

Existe, como podría advertirse desde ahora, una relación entre la innovación y la forma en la que se aprovecha la propiedad intelectual. Hacemos énfasis en que no es la mera existencia de los derechos de propiedad intelectual lo que asegura los beneficios esperados, sino que la posibilidad de maximizar tales beneficios depende en buena medida de la aproximación (enfoque) que tengan los titulares de derechos de propiedad intelectual hacia sus propios intangibles.

En el presente trabajo, los autores queremos presentar algunas consideraciones básicas en torno a la importancia de ese "enfoque" adecuado, o, para decirlo de forma más académica, nos interesa reflexionar sobre la importancia de la gestión estratégica de la propiedad intelectual. Los autores advertimos que si bien es relativamente frecuente encontrar trabajos que ponen énfasis en los aspectos legales generales en torno a los derechos de propiedad intelectual (reflexiones sobre la adquisición del derecho, la forma de oponerse a derechos pretendidos de terceros, la forma de defender los derechos, la extinción de los derechos, las limitaciones estructurales o temporales de los derechos, entre otros), es, por el contrario, infrecuente encontrar algún trabajo orientado a revelar el pliego de oportunidades de negocios que se presenta a los titulares de derechos de propiedad intelectual.

Quizás esta incomprensión respecto de las oportunidades disponibles a partir de una gestión adecuada de la propiedad intelectual, explique el porqué la adquisición de derechos de propiedad intelectual todavía no es visualizada por muchos empresarios (incluso exitosos) como una inversión esencial. Del mismo modo, los abogados dedicados a la propiedad intelectual suelen ser vistos como profesionales especializados en los trámites de adquisición de derechos, cuando resulta evidente que esta visión -parcializada, por cierto- dista de ser el centro de nuestra atención profesional. 


\section{Alternativas de gestión de la propiedad intelectual}

A menudo, los titulares de derechos de propiedad intelectual creen que la única o la mejor forma de emplear sus titularidades es ejercer la facultad de excluir a otros. Esta visión, aunque válida, enfrenta dos riesgos principales.

El primero es el elevado costo de oportunidad que implica, debido a que el ejercicio del derecho suele implicar dejar de lado alternativas de negocios. El segundo es que presupone un conocimiento exacto de las fronteras entre lo que el titular puede exigir y lo que debe tolerar. Aunque estas fronteras deben ser claras para los abogados, nuestro consejo legal es también costoso. Este último aspecto no es menor en un país como el Perú, en el que no es extraño encontrar a algún titular de derechos de propiedad intelectual con la idea falsa de que por ser titular puede impedir a todos realizar cualquier tipo de acto que le parezca que afecta su derecho.

Del lado de los que quieren incursionar en un mercado sin derechos de propiedad intelectual propios, suele creerse que la mejor forma de abrirse camino es cuestionar la validez de los derechos de terceros, lo cual, como es evidente, importa un elevado costo de litigación. La gama de oportunidades, también en este caso, es más amplia que la simple elección entre abstenerse de hacer algo y hacerlo con la creencia de que una pretensión de nulidad podría salvarnos en el supuesto de que el titular nos denuncie por una presunta infracción a sus derechos.

Los profesores Fisher y Oberholzer-Gee (2013) han desarrollado estas ideas que hemos comentado preliminarmente, y han construido un mapa en el que se exponen las particularidades y riesgos de cada alternativa existente. Para los efectos de este trabajo, vamos a tomar el esquema básico empleado por ellos, consignando en la columna de la izquierda las cinco opciones generales para los titulares de derechos, y en la columna de la derecha las cinco opciones generales para quienes quieren realizar un negocio en el que previsiblemente se toparán con derechos de propiedad intelectual asignados a terceros: 
1) Ejercer poder de mercado

2) Vender

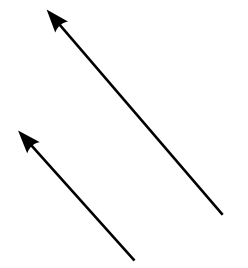

1) Ejercer un privilegio legal

2) Desarrollar alternativa

3) Obtener permiso

3) Licenciar PROPIEDAD INTELECTUAL

4)

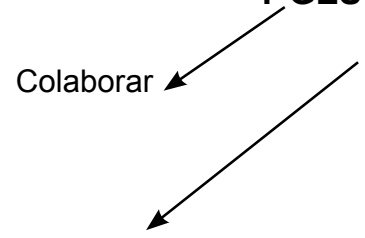

5) Donar

Gráfico n. ${ }^{\circ} 1$

El esquema presentado, que tiene apenas alguna modificación puntual y un cambio de estilo, representa un importante aporte de los autores ya mencionados ${ }^{2}$. La elección entre tales alternativas requiere de un análisis costo-beneficio detenido, que implica considerar las particularidades de cada legislación nacional (Fisher \& Oberholzer-Gee, 2013). El sistema legal influye en el nivel de rentabilidad de cada opción, y, de este modo, incide directamente en las elecciones preferidas por los individuos y en la posibilidad de acelerar o atrasar el nivel de innovación.

Cuando nos referimos a estrategias para la propiedad intelectual y la innovación en las empresas, hacemos referencia a una cuestión de importancia capital, porque permite realizar una estrategia y un planeamiento cuyos resultados podrán obtenerse a mediano y largo plazos. Los derechos de propiedad intelectual aportan beneficios de diversas

2 Los autores Fisher y Oberholzer-Gee actualizan de forma permanente varios mapas trabajados por ellos. Todos sus mapas pueden ser visualizados en el link: http://cyber.law.harvard.edu/people/tfisher/IP/Strategic_Management.htm 
maneras. Al proporcionar incentivos o premios a la innovación y nuevos emprendimientos, por la determinación o la definición de activos de propiedad intelectual y por la difusión de técnicas y control de tales activos, los beneficios de este tipo de derechos son un poderoso motor para la innovación (Pitkethly , 2007).

\section{Nivel de inversión de capital de las empresas en gestión adecuada de la propiedad intelectual}

Si la propiedad intelectual nos presenta alternativas tan valiosas, ¿por qué las empresas invierten poco (o nulo) capital en la gestión adecuada de propiedad intelectual? Consideramos que puede existir una serie de factores relacionados con la poca gestión o falta de ella, asociados básicamente al desconocimiento de los beneficios a futuro que este tipo de protección puede generar, más allá de los costos iniciales de inversión que este tipo de intangibles requiere.

El rol informativo que debe desempeñarse suele implicar una labor ardua que no solamente debe recaer en manos del Indecopi o de las instituciones del gobierno creadas para promover proyectos de investigación, desarrollo e innovación, como es el caso del FINCyT ${ }^{3}$, sino de todos los actores que giran en torno a la creación de contenidos e investigación con propósitos comerciales o sin estos, con la finalidad de fortalecer el sistema de la propiedad intelectual y ponderar sus ventajas.

En el Perú, cuando una persona decide emprender sus actividades de forma legal, lo primero en lo que se enfoca es en formalizarse. De la revisión de la Guía para la Constitución y Formalización de Empresas del Ministerio de la Producción ${ }^{4}$, se advierte que los pasos a seguir son:

3 El 19 de julio de 2006, el Gobierno del Perú y el Banco Interamericano de Desarrollo (BID) suscribieron el contrato de préstamo n. ${ }^{0}$ 1663/OC-PE, el cual dio origen al Programa de Ciencia y Tecnología. El 30 de enero del 2007 se instaló el consejo directivo de dicho programa en el Perú y se creó el Fondo para la Innovación, la Ciencia y la Tecnología (FINCyT), con la finalidad de promover proyectos de investigación, desarrollo e innovación. Los recursos de ese programa provienen del crédito otorgado por el BID y del tesoro público del Gobierno peruano. Fuente: http://www.fincyt.gob.pe/web/elprograma.html

$4 \mathrm{Al}$ respecto, ver: http://www.crecemype.pe/portal/images/stories/files/Guia_ Constitucion_empresas.pdf 
i) Decisión de qué tipo de persona le conviene para el negocio que va a realizar.

ii) Constitución y registro de la empresa misma (en la modalidad elegida) ante la Sunarp.

iii) Obtención de RUC para efectos tributarios ante la Sunat.

iv) Inscripción en el Registro Nacional de Micro y Pequeñas Empresas (Remype), dependiendo de si es micro o pequeña empresa.

v) Registro en Essalud para dar cobertura voluntaria u obligatoria a sus empleados y derechohabientes.

vi) Obtención de licencias o permisos para iniciar el giro del negocio (Ministerio de Agricultura, Mincetur, Ministerio de Educación, Ministerio de Energía y Minas, Ministerio de Trabajo, Digesa y Digemin $)^{5}$.

vii) Obtención de licencia municipal de funcionamiento.

viii) Legalización de libros contables.

Nótese que la mencionada Guía del Ministerio de la Producción es una pauta para la formalización de empresas en general, por lo que no necesariamente corresponderá a una orientación que deba seguirse, para el caso de empresas cuyo componente sea de activos intelectuales.

En tal escenario, ¿qué sucede con las empresas que deciden enfocarse en la explotación de nuevos emprendimientos con alto capital intelectual, como podría ser el caso del desarrollo de un software, comercio electrónico, entre otros? Para este tipo de empresas, lo ideal es empezar a planificar su estrategia desde la concepción misma del negocio, para ser un nicho de mercado o para diferenciarse del resto de empresas

5 Cabe precisar que de la revisión de la mencionada Guía únicamente se advierte que se hace referencia al Indecopi como parte de los actores de los registros y autorizaciones, así como se coloca una tabla de aranceles del TUPA de la misma institución, pero no se hace una explicación respecto de los beneficios que podría generar contar con derechos de propiedad intelectual, como sí se explican los beneficios y ventajas de los pasos previos para la formalización de los negocios. Asimismo, de la revisión de otras páginas web se advierte que únicamente se contemplan como pasos importantes para la constitución de las empresas los temas de personería jurídica, realización de trámites ante la autoridad tributaria, de trabajo y municipal (véase, por ejemplo: http://www.crecenegocios.com/pasos-para-constituir-una-empresa). 
competidoras, para lo cual, como paso previo, deberá identificar sus activos intelectuales presentes y potenciales.

Debe tenerse en cuenta que, con la innovación basada en la tecnología, el sistema de propiedad intelectual, si bien empieza como ideas o iniciativas novedosas, tiene una implicancia estratégica que deberá ser delineada cuidadosamente a efectos de salvaguardar y custodiar a este tipo de empresas. Entonces, llevar al mundo empresarial derechos de propiedad intelectual y poder vivir de tales derechos, implica ir más allá del registro de una marca, presentar una solicitud de patente o solicitar una inscripción de obra, ver El Peruano para advertir que un signo que se ha publicado no se parezca al que estamos solicitando, o presentar una acción por infracción en cualquiera de sus modalidades.

Contar con derechos de propiedad intelectual implica la gestión de dichos activos intangibles (es decir, realizar un seguimiento constante para proteger, cuidar, hacer enforcement y monitoreo), no solo para que nuestro producto y servicio se posicionen en el mercado, sino también porque contar con una patente, una marca registrada, un software, tener un know how, son activos intelectuales que se construyen con el tiempo, y protegerlos es crucial para el desarrollo del negocio y del éxito empresarial. Esta es una ventaja competitiva que provee una serie de herramientas para dejar a los competidores fuera del mercado e identificarnos como únicos.

En este escenario, nos planteamos: ¿cómo diseñar lineamientos que permitan la incorporación de los derechos de propiedad intelectual como herramienta de gestión estratégica en las empresas? Es decir, ¿Cómo contar con una gestión eficaz de los derechos de propiedad intelectual para que las empresas puedan utilizar sus activos intangibles para ser más competitivas?

Gestionar eficazmente un activo intelectual, como es la propiedad intelectual, es definir objetivos concretos y medibles, con la finalidad de determinar nuestro posicionamiento en el mercado y maximizar los beneficios. Una vez definido ello, es necesario determinar si nuestra estrategia es realizada por nuestra empresa aisladamente considerada, o vía la cooperación con otros actores, con la finalidad de no solo compartir recursos económicos, sino también experiencia, riesgo y beneficios, los cuales se plasmarán en los contratos y acuerdos que se firmarán, es decir, los recursos externos con los que se cuenta para dotar de dinamismo el sistema de propiedad intelectual que pretendemos consolidar. 
Reviste igual importancia considerar los recursos internos con los que cuenta una empresa para poder llevar a cabo este posicionamiento que se pretende lograr, habida cuenta que el "insumo" principal vendría a ser el capital humano que trabaja para y por la empresa, así como uniformizar cualquier y toda política que se tenga -o se pretenda tenersobre propiedad intelectual, con el fin de lograr una adecuada explotación económica, que más adelante se traducirá en resultados.

Entonces, para poder gestionar adecuadamente nuestros derechos de propiedad intelectual, se deben considerar tanto los recursos externos como los internos de una empresa. En efecto, como señala Kalanje (2014):

Para ello, la empresa debe llevar a cabo una evaluación de la propiedad intelectual, es decir, un procedimiento que permita determinar todos los derechos y activos de propiedad intelectual existentes o potenciales que utiliza o puede utilizar la empresa, y protegerlos, así como determinar claramente el ámbito de aplicación y el régimen de propiedad. No es sorprendente que, al efectuar un análisis de la situación de la propiedad intelectual, una empresa descubra que posee muchos activos de propiedad intelectual aunque estaba convencida de que no poseía ninguno, y que deba reflexionar sobre las medidas a tomar para protegerlos jurídicamente y aprovecharlos al máximo. Esta evaluación podría sentar las bases para la elaboración de un plan y una estrategia de gestión de los activos de propiedad intelectual [...].

Y es que el proceso de innovación que acompaña y va de la mano con los activos de propiedad intelectual, es un proceso complejo y de riesgo, el cual es dinámico. Citemos un ejemplo: el software. Este es dinámico por sí mismo, y, con el tiempo, cambiante de acuerdo al territorio y espacio donde se desea realizar su explotación y utilización. Así, por ejemplo, en países como el Perú, la protección de éste es a través del derecho de autor, mientras que en otros países la protección se puede ejercer mediante patentes de software, como es el caso de Estados Unidos y Argentina, por lo que lograr una adecuada apropiabilidad sobre los resultados que se generen dependerá de la estrategia que se desee utilizar, ya que la tecnología es cambiante.

Asimismo, debe tenerse en cuenta que para lograr "innovar" no necesariamente se requiere que el producto, servicio o proceso sea completamente nuevo o disruptivo. Podemos lograr innovar en determina- 
do sector únicamente, con la "adaptación" de determinada tecnología a un sector o a un rubro al que antes no pertenecía. En efecto...

[...] las empresas trasnacionales se apropian de cuotas de mercado internacional a través de sus estrategias tecnológicas específicas. En cambio, los países en desarrollo en general no tienen empresas que se caractericen por producir las nuevas tecnologías, pero en algunos casos las utilizan a través de diversos medios (licencias, importación de maquinaria y equipo, personal calificado, etc.). En estos países, los DPI son instrumentos para acceder a la tecnología extranjera y no propiamente instrumentos de apropiación de beneficios, aunque existan. En las últimas décadas, algunos países en desarrollo han aumentado considerablemente la producción de elementos de alta tecnología a través de empresas maquiladoras, pero ni diseñan estos productos y, en muchos casos incluso, no los consumen. (Aboites, 2006)

En el cuadro que a continuación se muestra, desarrollado por Schmidt y Druehl (2008), podemos apreciar los diversos tipos de innovación: 


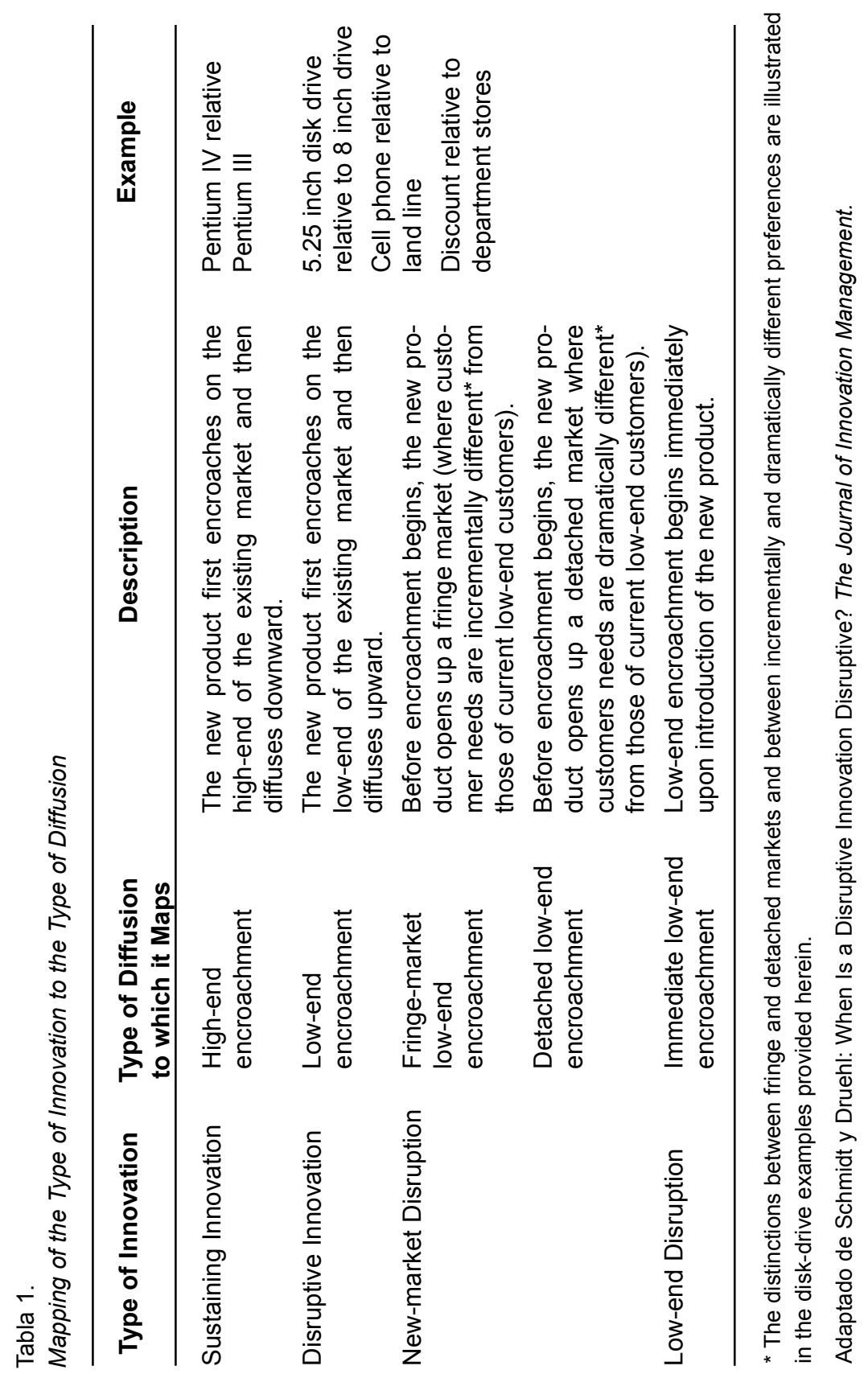




\section{Marco general para crear una estrategia basada en derechos de propiedad intelectual}

La primera decisión que los emprendedores, universidades, empresas y todo aquel que desee gestionar estratégicamente su propiedad intelectual deberá tener en cuenta, es determinar si lo que se desea explotar va a generar algún tipo de derechos y de qué tipo. Si la respuesta es positiva, ello bastará para empezar a crear una estrategia. Muchas veces se considera que si un emprendimiento genera, por ejemplo, una patente o un derecho de autor, este excluye otro tipo de protección (por ejemplo, la protección marcaria), cuando no es así.

Una vez trazada la línea de lo que se pretende explotar, se deberá crear un mapa conceptual de lo que se pretende llevar a cabo, con la finalidad de determinar ex ante qué es y cómo se pretende crear una estrategia previa a la gestión de la misma. El mismo ejercicio deberá realizarse ex post para la medición de resultados y replanteamiento de estrategias.

Para ejemplificar lo anterior, a continuación hemos diseñado un esquema que podría servir de pauta inicial, el cual dependerá de los factores económicos, territoriales, legales, condiciones para el desarrollo y explotación de intangibles, entre otros: 


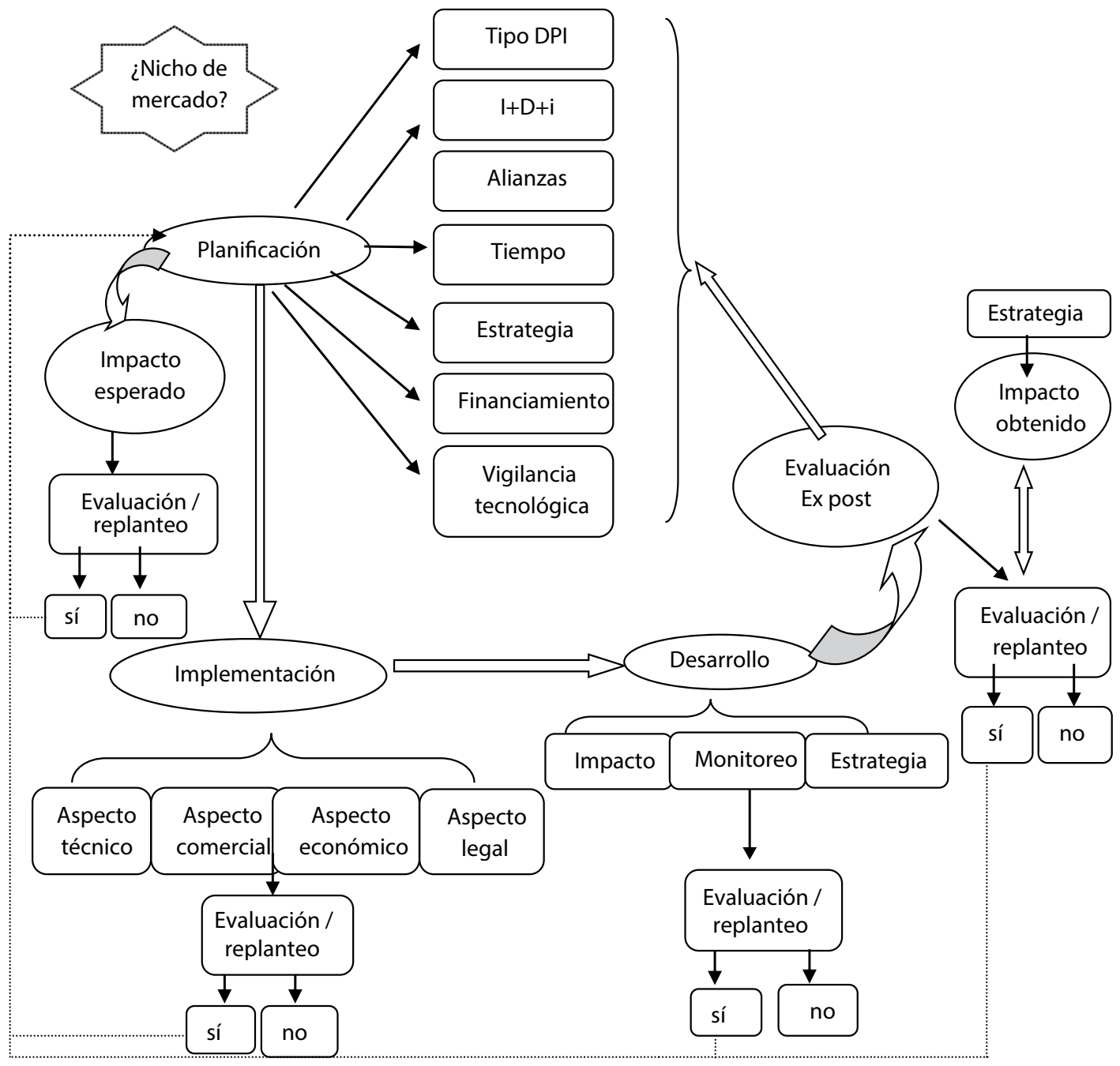

Gráfico n. ${ }^{\circ} 2$

Elaboración propia

Las etapas descritas previamente deberán ir acompañadas del flujo de información adecuado, con la finalidad de poder implementar y mediar la estrategia a corto, mediano y largo plazos. Así, consideramos que el diseño -y replanteo- de una estrategia para la gestión de la propiedad intelectual, se divide en cuatro etapas, que explicamos en seguida. 
En la primera etapa, la planificación, es importante determinar sobre qué tipo de derecho de propiedad intelectual vamos a ejercer la explotación económica. Es aquí donde definiremos si nuestro producto o proceso requiere de (y de cuánta) investigación, desarrollo e innovación, para poder introducir al mercado nuestro proyecto. Igual de importante es trazar una línea de tiempo que nos permitirá no solo definir el trabajo que desarrollaremos y su valor (tiempo, personal requerido, entre otros), también nos facilitará -si estamos en búsqueda de financiamiento- poder aplicar a los concursos para obtener financiamiento, inversionistas ángeles, ir en búsqueda de capitales de riesgo, capitales semilla, entre otros.

Como hemos indicado previamente, la planificación es la etapa inicial a través de la cual se empezará a delinear la estrategia, teniéndose en cuenta la tecnología que desarrollaremos y los beneficios que se pretenden lograr a corto, mediano y largo plazos.

Resulta de importancia medular, igualmente, decidir si queremos realizar la explotación económica a través de una start-up, spinout, o a través de cualquiera de las formas empresariales contempladas en la Ley General de Sociedades (sociedad anónima, sociedad de responsabilidad limitada, entre otras).

Cuando hacemos mención de las formas tradicionales de explotación empresarial, no significa que las start-up o spinout sean nuevas categorías de personas jurídicas, sino que estas son nuevas formas empresariales (iniciativas) que implican una estrategia diferente de entrada al mercado -y también de permanencia-, aunque la personería jurídica de estas deba ser necesariamente una de las formas empresariales contempladas en la Ley General de Sociedades.

Para adelantar un poco sobre este asunto, debe mencionarse que las start-up o spinout son empresas emergentes que se apoyan en la tecnología y nuevas formas de hacer negocios. Los rubros son diversos, desde la agricultura, las aplicaciones para smartphones, hasta simples ideas que innovan el mercado o los procesos de comercialización de los productos y la investigación aplicada. La generalidad de las start-up o spinout posee un derecho de propiedad intelectual que les otorga una ventaja competitiva frente a otra empresa.

En la segunda etapa, la implementación, se debe dar inicio a la estrategia diseñada, contemplándose todos los aspectos a los que el emprendimiento podría dar lugar, evaluando y replanteando los objetivos 
trazados, con la finalidad de poder enfocarlos adecuadamente al momento de poner en marcha el emprendimiento. Asimismo, debe tenerse en cuenta que podrían existir algunos derechos -para el caso que nos ocupa, los DPI- que podrían surgir a consecuencia de la puesta en marcha de la estrategia planteada.

La tercera etapa, el desarrollo, comprende la evolución del proyecto en marcha. Esta etapa abarca la medición y el replanteo de la estrategia, debido a que podrían surgir cuestiones como consecuencia de la implementación del emprendimiento, como puede ser la necesidad de establecer licencias cruzadas para el caso de patentes, o la utilización de obras derivadas, entre otros aspectos. De igual forma, en esta etapa se deben vislumbrar los objetivos de lo que la estrategia persigue, de acuerdo con los objetivos inicialmente trazados. En esta fase existe la necesidad de determinar si la estrategia deberá replantearse para conseguir los objetivos trazados.

La evaluación ex post consiste en medir y valorizar, a través de un tercero, los resultados de la estrategia y del planeamiento desarrollados, con la finalidad de medir su impacto directo e indirecto. Es en este momento cuando generalmente las empresas grandes ofertarán algún tipo de participación que quisieran tener en el emprendimiento, y, a través de los rendimientos económicos, la empresa podrá acceder al sistema financiero peruano para poder ser sujeto de crédito, al demostrar solvencia económica mediante los resultados financieros expresados en sus balances.

Cabe precisar que ello no enerva que, en las etapas anteriores, los inversionistas (ángeles, capital semilla o de capitales de riesgo) no hayan apostado previamente por el emprendimiento, o que este haya podido ser sometido a un elevator pitch. Un elevator pitch es una herramienta que pretende dar una idea general acerca de un producto, servicio, proyecto $u$ otra solución, que da inicio a una conversación ${ }^{6}$ y que podría ser impactante para un inversionista. La intención es que la idea pueda ser expuesta de manera sencilla y en poco tiempo.

De otro lado, previamente hemos indicado que existe una relación entre la innovación y la forma en la que se aprovecha la propiedad intelectual. En efecto, la gestión de este tipo de derechos permite la

6 http://elevatorpitchessentials.com/essays/ElevatorPitch.html 
maximización de los beneficios derivados de estos, que a su vez tienen efectos directos en la competitividad, productividad y tiempo de llegada al mercado.

Históricamente, las estrategias de los inventores para capturar el valor de sus invenciones era bastante simple: se centraban en la comercialización de los productos (Al-Aali y Teece, 2013), hecho que dista de lo que en la actualidad se requiere para posicionar un producto, servicio o proceso basado sobre un capital intelectual (intangible) o con alto grado tecnológico. A modo de ejemplo podemos citar un smartphone. Este posee una marca, que será el medio a través del cual los consumidores podrán solicitarlo y reconocerlo en el mercado y por la que marcará la diferencia con sus competidores. Asimismo, dicho producto contendrá aplicaciones, las cuales serán producto de patentes propias, licencias con terceros y patentes cruzadas. A su vez, dicho producto podrá tener un diseño industrial y derecho de autor sobre las aplicaciones que pueden correr en la plataforma, y descargarse en el propio producto.

Para los casos de productos y procesos de alto grado tecnológico (como es el caso de los productos farmacéuticos y biotecnológicos, desarrollo de aplicaciones y dispositivos en general, nanotecnología, entre otros), debemos tener en cuenta que estos pasan por un proceso de investigación, desarrollo e innovación $(\mathrm{I}+\mathrm{D}+\mathrm{i})$, realizado por una empresa, una universidad, o en alianza público privada, con la finalidad de determinar las ventajas competitivas de los mismos, para posteriormente determinar su viabilidad de desarrollo. En tal sentido, vemos que sobre un producto pueden existir una serie de derechos, y estos le podrían corresponder a más de una persona natural o jurídica.

Ahora bien, el producto, proceso o servicio que se pretende explotar, determinará el modelo de negocio, el cual deberá competir con los ya existentes. Dependerá de la estrategia elegida para marcar la pauta de diferenciación respectiva, es decir, si esta se enfoca desde el marketing, el producto, servicio o proceso en sí, o a través de la comercialización, entre otras.

\section{Tipos de estrategias con relación a la gestión de la propiedad intelectual}

Contar con una estrategia de propiedad intelectual no solo confiere, entre otros aspectos, la posibilidad de abarcar una cuota importante del 
mercado y conquistar nuevos, sino también poder utilizar recursos compartidos, abaratar costos e influenciar el mercado. No existen recetas para llegar a tener éxito con el planeamiento, pero sí existen herramientas que permiten hacer una proyección de lo que ello implica.

Previamente, hemos indicado que la gestión de los derechos de propiedad intelectual debe versar sobre qué tenemos, con la finalidad de delinear cómo se implementará, lo cual deberá estar alineado con los objetivos de la empresa y la misión y visión de la misma.

Suele pensarse que, para tener éxito, una empresa debe llegar primero al mercado con la finalidad de capturarlo, pero ello no necesariamente es así. Generalmente, las empresas que llegan primeras al mercado tienen la carga de soportar el costo de las innovaciones así como el costo del lead time, es decir, del tiempo de lanzamiento del producto, el cual podría tener un efecto contrario al deseado debido a las barreras de entrada, como pudiera ser que una tecnología se encuentre asentada, por lo que el nuevo producto podría no tener la acogida necesaria.

Asimismo, considerando el dinamismo del mercado, las empresas consolidadas también soportan la carga de las innovaciones disruptivas, que, como ya hemos visto, son aquellas que surgen con la finalidad de ganar mercado y quitar a las empresas consolidadas su posición. Este es el caso de Apple, que surgió para competir con IBM, para el caso de los ordenadores personales. Otro caso que ejemplifica este tema es el del surgimiento de la fotografía digital y su preferencia por parte de los consumidores, lo cual afectó a las empresas de este rubro, como pasó con Polaroid y Kodak. Esta última, en enero de 2012, anunció su quiebra y entrada a reestructuración ${ }^{7}$. No obstante ello, en el año 2013, dicha empresa anunció haberse recuperado de esa situación.

Robert Pitkethly (2007) refiere que aunque existen diferentes justificaciones a los sistemas de propiedad intelectual y las diferentes estrategias nacionales, para su aplicación, existen cuatro roles en este sistema: i) la propiedad intelectual actúa como un sistema de incentivos para la innovación, ii) actúa como un paquete de activos intelectuales, iii) permite la difusión de información técnica, y iv) permite controlar los activos intelectuales.

7 http://www.bloomberg.com/news/2013-09-03/kodak-exits-bankruptcy-as-printer-without-photographs.html 
Asimismo, dicho autor refiere que la misión de un sistema de propiedad intelectual que ofrece incentivos o premios a la innovación, es que estos se logren a través de la protección mediante la restricción de su uso por parte de terceros no autorizados. De otro lado, la explotación de los activos intelectuales puede darse de varias maneras, siendo el más conocido el esquema de licenciamiento. Igualmente, la difusión de la información permite que se conozca el contenido de este tipo de derechos, y evita que los free riders se aprovechen de la misma sin que el titular haya tomado conocimiento. Finalmente, el control de los activos intelectuales dependerá de si previamente este se ha otorgado.

Los componentes que forman parte de una estrategia de propiedad intelectual pueden dividirse, de acuerdo con Pitkethly (2007), en dos, a saber: a) estrategia externa de propiedad intelectual y b) estrategia interna de propiedad intelectual. La primera se refiere a los componentes externos que podrían ser materia de litigio, licenciamiento, entre otros; mientras que la segunda hace referencia a los recursos que se encuentran en el interior de la organización o empresa, tales como información, coordinación y manejo de la misma.

Para poder ejemplificar con meridiana claridad lo antes mencionado, consideramos que existen dos tipos de estrategias generales que nos permitirán manejar adecuadamente el portafolio y la gestión de derechos de propiedad intelectual, a saber: a) manejo de portafolio por cuenta propia, y b) manejo de portafolio por asociatividad o por terceros.

El primero de los citados (manejo de portafolio por cuenta propia) refiere la existencia de un titular que ostenta un derecho de propiedad intelectual, y este es manejado de forma directa, sin intermediarios. Ejemplo de lo mencionado vienen a ser los esquemas de licencias, cesiones de derecho, obtención de la titularidad por contrato, celebración de un contrato de transferencia de tecnología, franquicias, know how, entre otros esquemas.

En el segundo de los mencionados (manejo de portafolio por asociatividad o por terceros) hacemos referencia a los esquemas colaborativos a través de dos o más empresas diferentes, sean o no del mismo sector económico. Citemos un ejemplo: el caso del Golden Rice o Arroz Dorado (Krattiger, Potrykus \& Mayer, 2007), el cual es una variedad de arroz a la que se ha introducido una serie de componentes para ser llevado a países de extrema pobreza, como los africanos, donde la deficiencia vitamínica genera la ceguera y la muerte de miles de niños. Con la fina- 
lidad de explotar dicha innovación, se creó un consorcio llamado ProVitaMinRice, a fin de biofortificar una variedad de arroz GM, propia de Filipinas y Taiwán, e introducirle un alto contenido de ß-caroteno, vitamina E, proteína, hierro y zinc, utilizando para tales efectos las patentes cedidas por varias empresas biotecnológicas como el grupo Syngenta, el Centro de Biociencias Aplicadas de la Universidad de Freiburg, entre otras, y contó con el apoyo de la Fundación de Bill\&Melinda Gates, así como del USAID. Debe precisarse que este nuevo producto tendrá fines humanitarios y no comerciales.

Otro esquema colaborativo es el ejemplo de un clúster, el cual no tenemos consolidado en el Perú. El clúster es una aglomeración de empresas dentro de un determinado territorio, con la finalidad de desarrollar un sector tecnológico (como el caso del Silicon Valley) o un producto, como podría ser el clúster del salmón y vitivinícola en Chile (o el clúster del queso en Francia).

En este tipo de esquemas colaborativos, varias empresas independientes, titulares de diversos derechos de propiedad intelectual, podrían desarrollar proyectos en conjunto, cada cual aportando sus titularidades, y generar un único producto o servicio competitivo final, donde todas y cada una de las empresas intervinientes puedan ser las titulares del mismo y puedan establecer un esquema de cesión.

Ahora bien, habiendo trazado nuestra estrategia de propiedad intelectual, a continuación deberá trazarse la estrategia innovadora y de competitividad. Fasulino (2001) refiere que pueden optarse por cuatro estrategias: i) estrategia innovadora ofensiva (o también denominada de líder tecnológico), a través de la cual previamente se han identificado nuevas necesidades de mercado; ii) estrategia innovadora defensiva, a través de la cual se permite que los productos, procesos y servicios lleguen a más personas; iii) estrategia imitativa, la misma que es seguida por aquellas empresas que tienen un grado de innovación mínimo; iv) y estrategia oportunista, aquella que busca el punto más débil del competidor con la finalidad de evitar una confrontación directa.

Consideramos adicionalmente que otra opción que se puede explorar para llevar a cabo una adecuada gestión estratégica de los derechos de propiedad intelectual, es el esquema de acuerdos de desarrollo compartido, el cual aplica preferentemente para empresas que vienen de sectores diferentes, cuando no tienen la suficiente experiencia para desarrollar un producto o proceso innovativo y les resulta más conveniente entrar 
en un acuerdo con la finalidad de compartir los costos de producción, desarrollo de diferentes portafolios de propiedad intelectual.

Otra estrategia que los emprendimientos pueden implementar es la fusión con otras empresas, con la finalidad de integrar sus soluciones o productos, así como compartir recursos para repotenciarla. Tal es el caso de empresas grandes o medianas que adquieren empresas pequeñas, que puedan ser fácilmente integradas a los proyectos existentes de la compañía. A modo de ejemplo, cabe citar a la empresa Apple, que en el año 2002 adquirió la empresa Emagic -que era titular de un software para realizar música a nivel profesional-y otra pequeña empresa, Logic Pro, lo cual generó al interior de Apple la creación de una estación compuesta por un software de audio digital para perfeccionar el Itunes.

Finalmente, es importante mencionar también otro enfoque, esta vez anotado por Spruson y Ferguson (2007), y en el que se plantea que antes de formular una estrategia de propiedad intelectual, se deberá analizar la competencia que el proyecto o emprendimiento enfrentará en el sector pertinente, con la finalidad de determinar la posible ventaja competitiva.

\section{5. ¿Start-up o spinout?}

Previamente hemos señalado que las start-up o spinout son empresas emergentes que se apoyan en la tecnología y nuevas formas de hacer negocios. Los rubros son diversos: van desde la agricultura, las aplicaciones para smartphones, hasta simples ideas que innovan el mercado o los procesos de comercialización de los productos y la investigación aplicada.

Desde finales de 1990 llamaba la atención cómo en Estados Unidos existían empresas que podían comercializar la tecnología cuando provenían de centros de investigación o de universidades, dando origen a las spinout. Tal es el caso del surgimiento de Silicon Valley, el cual fue originado a través de la contribución de universidades como Stanford University.

A diferencia de las spinout, empresas que se han creado dentro de los centros de investigación y universidades, y cuyos recursos de investigación y desarrollo provienen de dichas instituciones, las start-up son empresas creadas fuera de las instituciones de investigación, y se dedican básicamente a la explotación de productos tecnológicos. Ambas 
comparten un componente intrínseco de toda innovación: el riesgo en el retorno económico de las inversiones realizadas.

\section{Cuestiones finales}

Cada emprendimiento surge como consecuencia de un proceso y concepción distintos y particulares, aunque todos parten de un común denominador: el conocimiento puesto en práctica a través de un producto, proceso o servicio que será colocado en el mercado. La propiedad intelectual es la plasmación de la dotación de valor de ese conocimiento, y su rentabilidad (o potencial rentabilidad) dependerá del negocio que se ponga en marcha. De acuerdo con la Organización para la Cooperación y el Desarrollo Económico (OECD, 2011)...

[...] en una economía basada en el conocimiento, la innovación es el factor clave para la creación, generación de empleo y, en términos más generales, el crecimiento económico. Las nuevas iniciativas de negocios y las empresas pequeñas y medianas (PYME) desempeñan un papel fundamental en el apoyo a la innovación y a su difusión a través de la economía, contribuyendo a la creación de empleos de altos salarios y la mejora de la productividad.

Como hemos advertido previamente, la propiedad intelectual pretende facilitar el proceso de "agregado de valor" a un determinado emprendimiento, para que este pueda ser apropiado y explotado adecuadamente. Si bien la faceta negativa (expresada en el derecho a excluir a los demás de otras formas de utilización) de la propiedad intelectual es una de las formas más comunes de utilización, no debemos perder de vista que esta nos presenta diversas opciones que trascienden la mera acumulación de activos. En pocas palabras, la propiedad intelectual, bien entendida y gestionada, puede ser, en sí misma, un importante aliado para el crecimiento y la consolidación de las empresas y de los mercados.

\section{Referencias}

Aboites, J. (2006). Innovación, propiedad intelectual y estrategias tecnológicas. Mundo siglo 21. Recuperado de http://www.mundosigloxxi.ciecas.ipn.mx/pdf/v02/05/07.pdf 
Al-Aali, Abdulrahman Y., \& Teece, David J. (2013). Towards the (Strategic) Management of Intellectual Property: Retrospective and Prospective. California Management Review, 55(4), pp. 15-30.

Fasulino, E. (2001). La innovación tecnológica. Argentina: Heliasta.

Fisher, W., \& Oberholzer-Gee, F. (2013). Strategic Intellectual Property Management-An Integrated Approach. California Management Review, 55(4), pp. 157-183.

Fisher, W., \& Oberholzer-Gee, F. (2013). Strategic Management of Intellectual Property [gráfico] recuperado de http://cyber.law.harvard. edu/people/tfisher/IP/Strategic_Management.htm

Greenlagh, C., \& Rogers, M. (2010). Innovation, Intellectual Property and Economic Growth. New Jersey: Princeton University Press.

Kalanje, C. (2004). Aprovechar al máximo el sistema de propiedad intelectual: Algo más que el "derecho a excluir". Recuperado de http://www.wipo.int/sme/es/documents/leveraging_ip.htm

Krattiger, A., Potrykus, I., \& Mayer, J. (2007). Golden Rice: A Product-Development Partnership in Agricultural Biotechnology and Humanitarian Licensing. En Krattiger, A. et al. Intellectual Property Management in Health and Agricultural Innovation: A Handbook of Best Practices (vol. 1). University of New Hampshire Scholars' Repository.

OECD. (2011). Intellectual Assets and Innovation. The SME dimension. United Kingdom: Turpin Distribution Services.

Pitkethly, R. (2007). IP Strategy. En Krattiger, A. et al. Intellectual Property Management in Health and Agricultural Innovation: A Handbook of Best Practices (vol. 1, pp. 459-473). University of New Hampshire Scholars' Repository.

Schmidt, G., \& Druehl, C. (2008). When Is a Disruptive Innovation Disruptive? The Journal of Innovation Management, 25(4), pp. 347-369.

Schmidt, G., \& Druehl, C. (2008). When Is a Disruptive Innovation Disruptive? [tabla] Recuperado de: The Journal of Innovation Management.

Spruson \& Ferguson. (2007). Intellectual Property Management: A Practical Guide for Electrical and Electronics Related Industries. Recuperado de http://www.spruson.com/wpcontent/uploads/2014/01/IP_Management_Guide_lowres.pdf 